\title{
COLLOIDON BABY WITH OPHTHALMIC INVOLVEMENT
}

Shrinivas M Ganagi ${ }^{1}$, Vishnu Prabhu², Sarita Gosalve ${ }^{3}$, Abijeeth ${ }^{4}$

\section{HOW TO CITE THIS ARTICLE:}

Shrinivas M Ganagi, Vishnu Prabhu, Sarita Gosalve S, Abijeeth. "Colloidon Baby with Ophthalmic Involvement". Journal of Evolution of Medical and Dental Sciences 2014; Vol. 3, Issue 71, December 18; Page: 15184-15186, DOI: $10.14260 /$ jemds/2014/4040

INTRODUCTION: Collodion baby is a rare, genetic heterogeneous skin disorder. It refers to a clinicentity used for newborns who are encased by a translucent, tight and parchment paper like skin sheets so called collodion membrane, on the entire body surface. ${ }^{1}$ Collodion baby is a phenotype which broadly describes the above condition which includes a number of phenotypes. The two most common phenotypes are lamellar ichthyosis and non-bullous congenital erythroderma which account for $75 \%$ of cases and others like Sjögren-Larsson syndrome, Netherton syndrome, Gaucher disease etc account for $15 \%$ of the cases. ${ }^{2}$ Lamellar ichthyosis which is more common, is an autosomal recessive condition caused by mutations in the transglutaminase-1 gene, defect on chromosome 14q11.Lid ectropion and ocular complications like exposure keratitis are seen commonly in colloidon babies. $^{3} 15$ day old male baby, first issue of a second degree consanguineously married couple, born at a gestation age of 36 weeks (normal vaginal delivery) was referred to ophthalmic institute for management of ectropion. Child was diagnosed to have lamellar ichthyosis at the paediatric referral institute. At birth baby weighed 2500 grams, length $48 \mathrm{~cm}$, head circumference of $34 \mathrm{~cm}$.

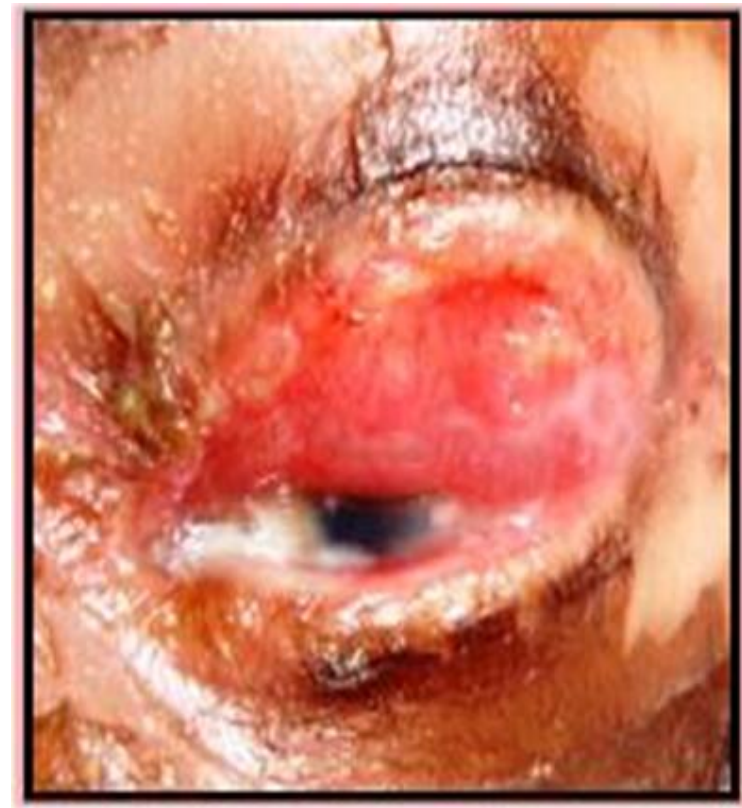

Figure 1

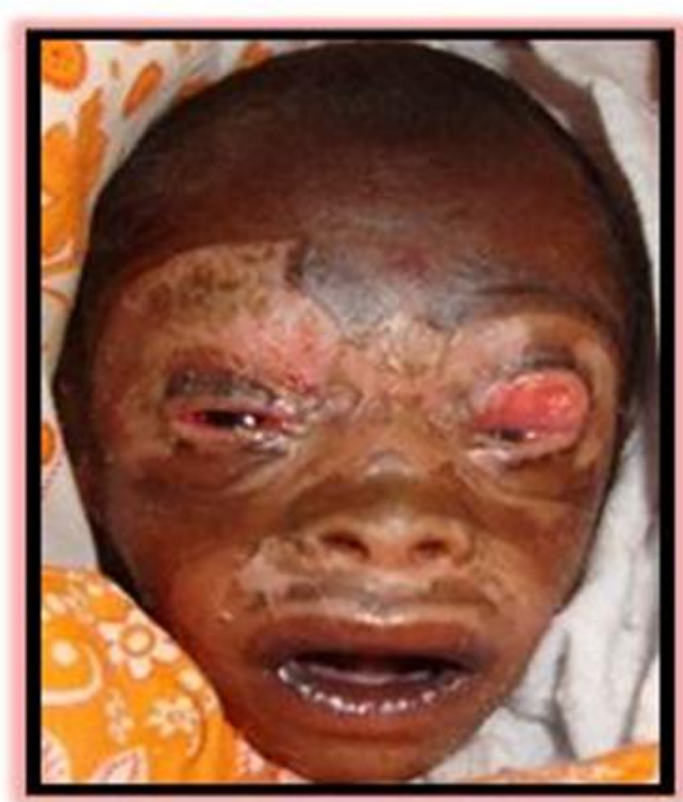

Figure 2 


\section{CASE REPORT}

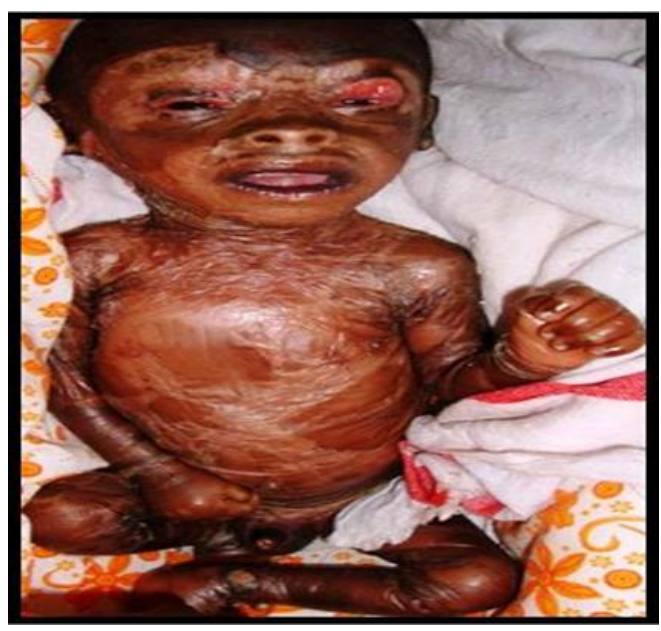

Figure 3

The vitals were maintained. General examination showed fissuring and peeling of the skin. Examination of the right eye showed loss of eyelashes and eyebrows, severe ectropion of upper lid, mucopururulent discharge, Fundus was normal. Examination of left eye revealed ectropion with loss of eyelash and eyebrows, cornea showed signs of exposure keratitis (Fig. 1), fundus could not be visualized due to corneal haze and exposure keratitis. There was eclabion (Fig. 2) and generalized glistening, taut reddish film stretched over the skin with fissuring and Peeling giving a "DIPPED IN HOT WAX" Appearance (Fig. 3). Nails were hypoplastic and there was joint stiffness. Staphylococcus aureus conjunctivitis was treated topical antibiotics and lubricants were prescribed. Referred back to institute of child health for further management.

Ocular complications include exposure keratitis secondary to ectropion, blepharitis, absence of the meibomian gland, trichiasis, madarosis, and absence of lacrimal puncta. Secondary corneal ulceration may occur due to exposure. Late presentation can lead to severe, sight-threatening complications like desmetocele and corneal perforation. The eyes can were treated with hourly instillation of lubricants and topical antibiotics. Frequent massage of the lid skin with lubricant ointment can be done. Wet saline gauze can be placed over the face, covering the eyes, to prevent exposure keratitis. Collodion baby possesses the high risk for systemic and skin complications. Its abnormal skin may cause heat \& fluid loss, easy infections, dehydration, electrolyte imbalance etc. There may be some systemic complications like pneumonia, body heat loss which require a multidisciplinary approach for management.

\section{CONCLUSION:}

1) The term collodion baby is used for newborns in whom all the body surface is covered by thick skin sheets called "collodion membrane" of which lamellar ichthyosis is the most common underlying cause.

2) Ectropion of lower lid is the most common complication. The ectropion may result in exposure keratitis as in our case

3) Management of collodion baby requires a multi-disciplinary approach. 


\section{REFERENCES:}

1. D Van Gysel, RLP Lijnen, SS Moekti,.Collodion baby: a follow- up study of 17 cases. J Eur Acad Derm Venereol; 2003, 16: 472-475.

2. Bhardwaj U, Phougat A, Dey $\mathrm{M}$, et al, A rare case of collodion baby with ophthalmic involvement. Nepal J Ophthalmol 2012; 4 (7): 184-186.

3. Obu HA. Adimora G. Chinawa JM.Colloidon baby. A series of 4 cases. Niger J Paed 2013; 40 (3): $307-310$.

\section{AUTHORS:}

1. Shrinivas M Ganagi

2. Vishnu Prabhu

3. Sarita Gosalve $\mathrm{S}$.

4. Abijeeth

\section{PARTICULARS OF CONTRIBUTORS:}

1. Associate Professor, Department of Ophthalmology, SIMS \& R C, Mukka.

2. Professor, Department of Ophthalmology, SIMS \& R C, Mukka.

3. Assistant Professor, Department of Ophthalmology, SIMS \& R C, Mukka.
4. Assistant Professor, Department of Ophthalmology, SIMS \& R C, Mukka.

NAME ADDRESS EMAIL ID OF THE CORRESPONDING AUTHOR:

Dr. Shrinivas M. Ganage, Associate Professor, Department of Ophthalmology, SIMS \& RC, Mukka-574146.

Email: srinivasgamigs123@gmail.com

Date of Submission: 22/11/2014.

Date of Peer Review: 24/11/2014.

Date of Acceptance: 13/12/2014.

Date of Publishing: 18/12/2014. 